\title{
The Error Analysis for the Remote Sensing of Water Vapor Data by Ground Based GPS in Tengchong, Yunnan Province
}

\author{
Youlong Zhao',2, Shunwu Zhou' ${ }^{*}$, Shuo Wang1,3, Jihua Sun ${ }^{4}$, Xin San ${ }^{1}$ \\ ${ }^{1}$ Collaborative Innovation Center on Forecast and Evaluation of Meteorological Disasters, Nanjing University of Information \\ Science \& Technology, Nanjing, China \\ ${ }^{2}$ Jinzhong Meteorological Bureau of Shanxi Province, Jinzhong, China \\ ${ }^{3}$ Guizhou Meteorological Service, Guiyang, China \\ ${ }^{4}$ Yunnan Meteorological Observatory, Kunming, China \\ Email: *zhou@nuist.edu.cn
}

How to cite this paper: Zhao, Y. L., Zhou, S. W., Wang, S., Sun, J. H., \& San, X. (2019). The Error Analysis for the Remote Sensing of Water Vapor Data by Ground Based GPS in Tengchong, Yunnan Province. Journal of Geoscience and Environment Protection, 7, 231-245.

https://doi.org/10.4236/gep.2019.79016

Received: July 24, 2019

Accepted: September 24, 2019

Published: September 27, 2019

Copyright (C 2019 by author(s) and Scientific Research Publishing Inc. This work is licensed under the Creative Commons Attribution International License (CC BY 4.0).

http://creativecommons.org/licenses/by/4.0/

\section{(c) (i) Open Access}

\begin{abstract}
Due to its special observation principle, GPS remote sensing atmospheric precipitation has the advantages of high time resolution and no weather conditions, and has been widely used in the research field of atmospheric precipitation. Using ground-based GPS precipitate water vapor data (GPS-PWV) and radiosonde-precipitate water vapor data (RS-PWV) that integrated by Radiosonde data, the error between GPS-PWV and RS-PWV in Tengchong is analyzed on its distribution of wet and dry seasons, also the difference between 00:00 UTC and 12:00 UTC. Results show that the RMSE of GPS-PWV and RS-PWV on both 00:00 UTC and 12:00 UTC are less than $5 \mathrm{~mm}$, they correspond with each other well and their correlation coefficient is above 0.95, additionally, GPS-PWV value is stable than RS-PWV value. On the whole, the value of GPS-PWV is slightly larger than RS-PWV. And the mean absolute error between them has higher values, $4.5 \mathrm{~mm}$ in 2011 and $4.7 \mathrm{~mm}$ in 2012 from May to October (local rainy season) and lower values, $2.8 \mathrm{~mm}$ in 2011 and $3.1 \mathrm{~mm}$ in 2012 in November to April (local dry season). Besides, the mean absolute error in the morning seems has a difference with its component in the evening. Specifically, it is bigger on 12:00 UTC than on 00:00 UTC and the mean absolute errors on 12:00 UTC of two years are $27 \%$ and $11 \%$ larger than errors on 00:00 UTC respectively. The correlation of mean absolute error and surface vapor pressure, surface air temperature is examined in this study as well. We achieved that the correlation coefficient between mean absolute error and surface vapor pressure, surface air temperature equals $0.32,0.37$ separately. Diverse characters of mean absolute error
\end{abstract}


under different precipitation conditions are also discussed. The outcome is that the mean absolute error has a higher value on rainy days and a lower value on clear days. However, during the precipitation periods, it appears that the mean absolute error and the rainfall situation don't agree with each other well, it is likely to change randomly.

\section{Keywords}

GPS-Derived Precipitate Water Vapor, Tengchong, Radiosonde Water Vapor, Mean Absolute Error, Seasonal Characteristics

\section{Introduction}

Water vapor is an important member of the atmospheric composition and is closely related to precipitation and surface air temperature (Zhai \& Zhou, 1997). At present, the methods for detecting atmospheric precipitation are radiosonde, microwave radiometer, satellite remote sensing observation and GPS remote sensing observation. Due to its special observation principle, GPS remote sensing atmospheric precipitation (hereinafter referred to as GPS-PWV) has the advantages of high time resolution and no weather conditions, and has been widely used in the research field of atmospheric precipitation. Since the 1990s, the ground-based GPS remote sensing observation of precipitation is carried out on a global scale. The accuracy of GPS-PWV (hereinafter referred to as RS-PWV) is usually tested by the sounding and precipitation (Root mean square error). The observation results of atmospheric precipitation in China's first GPS meteorological test show that the results of GPS-PWV and RS-PWV are basically the same, and the accuracy is $5 \mathrm{~mm}$ (Wang et al., 1999; Li et al., 1999). The results of other similar studies are also generally consistent. Among them, the accuracy of GPS inversion in the Beijing-Tianjin region is $2.90 \mathrm{~mm}$ (Liang et al., 2003); the accuracy of GPS-PWV in Chengdu is $3.09 \mathrm{~mm}$ (Li et al., 2006). In general, the accuracy of GPS-PWV in China is mostly between $2-4 \mathrm{~mm}$, while the accuracy in North America is about 1 - $2 \mathrm{~mm}$ (Duan et al., 1996); Japan is between 2.66 $3.70 \mathrm{~mm}$ (Ohtani \& Naito, 2000). Although there are some differences in the ground-based GPS-PWV errors in different regions, the accuracy is generally less than $5 \mathrm{~mm}$. It can be seen that the GPS remote sensing atmospheric precipitation has higher credibility in the existing observation technology.

At present, the GPS-PWV accuracy test and error analysis work in China has focused on the middle and lower reaches of the Yangtze River, North China, Central China and the West China Plain. The research on the ground-based GPS-PWV of the Qinghai-Tibet Plateau and its surrounding mountains is still rare. The study of atmospheric precipitation in the plateau and surrounding mountainous areas is mainly based on the sounding and precipitation. The research on the atmospheric water circulation process in the plateau and surrounding areas has an important place. The water vapor distribution, source and 
transportation of the plateau have always been concerned. However, the conventional sounding data is only twice a day, and the sounding station has little distribution in the plateau. However, the spatial and temporal distribution of atmospheric precipitation is complex and variable. The sounding distribution characteristics of the plateau and surrounding mountains cannot be fully revealed by relying on sounding data alone. In recent years, ground-based GPS stations established in the plateau and surrounding areas have provided new atmospheric precipitation data. The research shows that the GPS-PWV and RS-PWV results in the Qinghai-Tibet Plateau are in good agreement (Liang et al., 2007), especially in the eastern Tibet, GPS-PWV and RS-PWV have a high degree of fitting (Ma et al., 2016).

Although GPS-PWV has high precision in many parts of China, it should be tested for accuracy and error when applying analysis for specific regions. Tengchong is located in the western part of Yunnan Province and is an extension of the southeast corner of the Qinghai-Tibet Plateau. It is also a transitional area with a humid and semi-humid climate (Zhang \& Shen, 2008). The station also has sounding and GPS atmospheric precipitation data. Previously, there was little error analysis of the GPS-PWV at Tengchong Station. In the only study, the data used was shorter. The study pointed out that the atmospheric precipitation of Tengchong station's conventional sounding data points is close to the ground-based GPS remote sensing atmospheric precipitation. The difference between the two is (Yan et al., 2012), but it only made several comparison data in August 2010. Ren Juzhang et al. compared the GPS water vapor detection data of Yunnan Province with the three types of reanalysis water vapor data. The results show that the estimation of monthly average precipitation by reanalysis data is generally smaller than the GPS detection value (Ren et al., 2014). However, it is not possible to prove the reliability of the precipitation in the plateau and surrounding areas estimated by reanalysing the data. In addition, studies have shown that there are seasonal variations, morning and evening differences in water vapor detection bias in the plateau (Liang et al., 2012), and there are some differences in different precipitation conditions (Xiang et al., 2009). The climate of Yunnan Province is affected by the East Asian monsoon and has significant dry and wet transition characteristics. In general, it is divided into rainy season from May to October, and dry season from November to April (Fu et al., 2010). In order to test the accuracy of Tengchong Station GPS-PWV and analyze its error characteristics, using the ground-based GPS remote sensing data of the platform and the sounding and precipitation data in 2011 and 2012, the seasonal distribution characteristics of GPS-PWV error, morning and evening differences are analyzed comprehensively, and the relationship between error and meteorological factors such as temperature and humidity is analyzed, and the distribution of error under the condition of precipitation is analyzed.

\section{Data and Methods}

The ground-based GPS remote sensing atmospheric precipitation data used in 
this paper is the ground-based GPS site established by JICA (Japan International Cooperation Agency) project in Tengchong, Yunnan Province $\left(25.02^{\circ} \mathrm{N}, 98.50^{\circ} \mathrm{E}\right.$, altitude $1635 \mathrm{~m}$ ). Original GPS data provided, Data obtained from the calculation of atmospheric precipitation, temperature and relative humidity obtained by the Yunnan Institute of Meteorological Sciences (Sun et al., 2013); This paper uses the hourly atmospheric precipitation data from 2011 to 2012. Since the sounding data is twice daily (00:00 and 12:00 World Time), the simultaneous GPS-PWV is extracted for comparative analysis. The sample situation of GPS-PWV is shown in Table 1. The average rate of GPS-PWV is $22 \%$ in 2011, and the lack of measurement is mostly in September-January, while the average rate of default in 2012 is $13.5 \%$, the time period with more missed measurements is distributed in February, May and September. The sounding data is the simultaneous sounding data (water vapor pressure data of each level) at Tengchong Station $\left(25.01^{\circ} \mathrm{N}\right.$, $98.50^{\circ} \mathrm{E}$, altitude $1649 \mathrm{~m}$ ) provided by the National Meteorological Information Center (Figure 1). The sounding of the atmosphere can be obtained by using the sounding data through the integral (Zhai \& Zhou, 1997). The meteorological element data related to the GPS-PWV error is analyzed by the Yunnan Meteorological Bureau. The daily ground temperature, ground humidity, relative humidity and the hourly precipitation data of the Tengchong automatic station from 2011 to 2012 in Tengchong Station.

In order to accurately compare the difference between the two water vapor detection results, the GPS-PWV error is calculated using GPS-PWV and RS-PWV at the same time. When calculating, the GPS-PWV at the time of the missing measurement is taken. The error is calculated as the average of the absolute deviations of GPS-PWV and RS-PWV in different time periods. In addition, a synthetic analysis method is employed when analyzing the relationship between GPS-PWV error and temperature, humidity, and etc. Synthetic analysis method refers to a research method that uses various statistical comprehensive indicators to reflect and study the general characteristics and quantitative relationships of the overall socio-economic phenomena (Hua et al., 2007). The

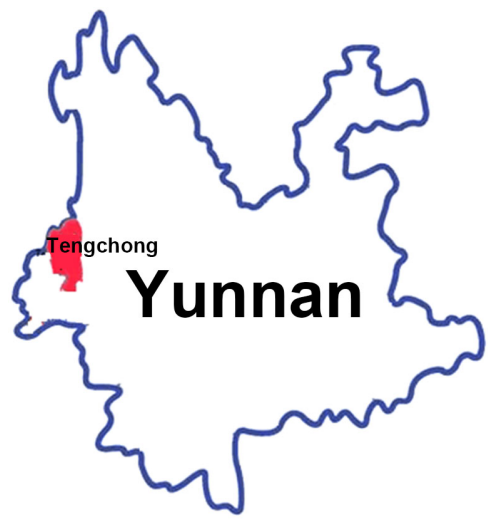

Figure 1. Tengchong's location in Yunnan Province, China. 
Table 1. Number of samples in 2011 and 2012 and different seasons.

\begin{tabular}{ccccc}
\hline & \multicolumn{2}{c}{2011} & \multicolumn{2}{c}{2012} \\
\cline { 2 - 5 } & $00: 00$ UTC & $12: 00$ UTC & $00: 00$ UTC & 12:00 UTC \\
\hline $\begin{array}{c}\text { Full year (samples/days of the year) } \\
\text { Rainy season (number of } \\
\begin{array}{c}\text { samples/days of rainy season) } \\
\text { Dry season (number of } \\
\text { samples/dry season days) }\end{array}\end{array}$ & $287 / 365$ & $281 / 365$ & $314 / 366$ & $320 / 366$ \\
\hline
\end{tabular}

variation coefficient of GPS-PWV and RS-PWV is expressed by the coefficient of variation coefficient $\mathrm{CV}$. The $\mathrm{CV}$ is the ratio of the sample mean value to the standard deviation. The larger the $\mathrm{CV}$, the larger the variable value of the variable data and the more unstable. Conversely, the variable data is stable.

\section{Results}

\subsection{Daily Variation Characteristics of GPS-PWV and RS-PWV}

In order to investigate the daily variation characteristics of atmospheric precipitation in Tengchong Station and verify the accuracy of the station GPS-PWV, the daily variation characteristics of GPS-PWV and corresponding time RS-PWV in 2011 and 2012 are analyzed. At 00 o'clock and 12 o'clock, both GPS-PWV and RS-PWV have consistent unimodal annual variation characteristics, both of which show that the atmospheric precipitation of the station has obvious seasonal variation characteristics, among them, From January to April, the amount of precipitation is low, the growth rate is slow, and it starts to increase rapidly after May, and it reaches the maximum value of the whole year from June. The high value of precipitation can last until the middle and late October. Reduced, and returned to the low period after November. After calculation, the correlation coefficients of GPS-PWV and RS-PWV in 2011 and 2012 are both above 0.95, while the correlation coefficient of similar research in China is between 0.57 and 0.94 (Li et al., 2006; Chen et al., 2009; Wang et al., 2014; Lu et al., 2014), indicating the GPS-PWV of Tengchong Station. RS-PWV has very good consistency. In addition, the accuracy of GPS-PWV for two years is no more than $5 \mathrm{~mm}$ at 00 o'clock and 12 o'clock, that is, Tengchong station GPS-PWV is very close to RS-PWV and has high credibility. However, the annual average coefficient of variation of GPS-PWV at 0:00 and 12:00 is 0.54 and 0.49 , respectively, while the RS-PWV is 0.59 and 0.57 , respectively. During the high-value period (rainy season) and low-value period of atmospheric precipitation (dry) the coefficient of variation $\mathrm{CV}$ of the two seasons also has similar distribution characteristics (Table 2), that is, under the condition of high correlation, the change of GPS-PWV is more stable than that of RS-PWV.

\subsection{Seasonal Differences in GPS-PWV Errors}

There is still a certain difference between GPS-PWV and RS-PWV under the condition of high degree of coincidence, and this error is especially significant 
Table 2. Distribution of annual coefficient of variation calculated for GPS-PWV and RS-PWV on 00:00 UTC and 12:00 UTC in 2011, 2012 and the seasonal value of it over their respective wet season and dry season.

\begin{tabular}{cccccccc}
\hline \multirow{2}{*}{ Water vapor years } & \multicolumn{2}{c}{ Full year } & \multicolumn{2}{c}{ Rainy season } & \multicolumn{2}{c}{ Dry season } \\
\cline { 3 - 8 } & & 00 & 12 & 00 & 12 & 00 & 12 \\
\hline \multirow{2}{*}{ GPS-PWV } & 2011 & 0.52 & 0.47 & 0.20 & 0.19 & 0.44 & 0.33 \\
& 2012 & 0.56 & 0.50 & 0.27 & 0.24 & 0.41 & 0.35 \\
\multirow{2}{*}{ RS-PWV } & 2011 & 0.57 & 0.53 & 0.22 & 0.21 & 0.55 & 0.45 \\
& 2012 & 0.60 & 0.58 & 0.30 & 0.27 & 0.54 & 0.50 \\
\hline
\end{tabular}

between May and October. It is indicated that the GPS-PWV error may have the same seasonal variation characteristics as the GPS-PWV itself. Previous studies have pointed out that there are seasonal variations in the detection of atmospheric precipitation (Liang et al., 2012). In order to understand the seasonal variation characteristics of GPS-PWV error in Tengchong Station, the monthly change of GPS-PWV error in 2012 at two moments with less measurement is analyzed. It can be seen from Figure 2 that there is a significant seasonal difference in the distribution of monthly mean error. Different from the unimodal annual variation of GPS-PWV, the monthly variation of error presents a bimodal characteristic, but Both are in the high value of the whole year between May and October (rainy season), and lower in the period of November to April (dry season); the situation is similar in 2011 (figure omitted).

The GPS-PWV error statistics in the rainy and dry seasons (Table 3) show that the annual average monthly error of Tengchong's GPS-PWV in 2011 is 3.7 $\mathrm{mm}$, of which the error in the rainy season is $4.5 \mathrm{~mm}$, while the dry season is small. The error is $2.8 \mathrm{~mm}$, but both GPS-PWV are larger than RS-PWV. The difference is that the altitude of the GPS station is lower than that of the sounding station, so that the GPS remote sensing atmospheric precipitation is larger than the sounding precipitation; in the second rainy season, the atmospheric precipitation is more than the dry season, resulting in errors. It will also increase during the rainy season. The results of the $\mathrm{T}$ test show that the seasonal difference of the GPS-PWV error for two years has passed the significance test of $\alpha=$ 0.05 , indicating that the error does have significant dry and rainy season differences.

\subsection{The Difference between GPS and PWV Error}

In addition to the obvious seasonal differences in GPS-PWV, the study also pointed out that RS-PWV is $3-4 \mathrm{~mm}$ lower than GPS-PWV (Nakanura et al., 2004), and is more obvious during the day (Wang \& Zhang, 2008). Similarly, the detection of atmospheric precipitation in the Qinghai-Tibet Plateau has a significant daily variation: at 12 o'clock, it is greater than 00 (Liang et al., 2012). In order to test whether the error of GPS-PWV at Tengchong Station also has differences between day and night, further statistical analysis was made. From the 

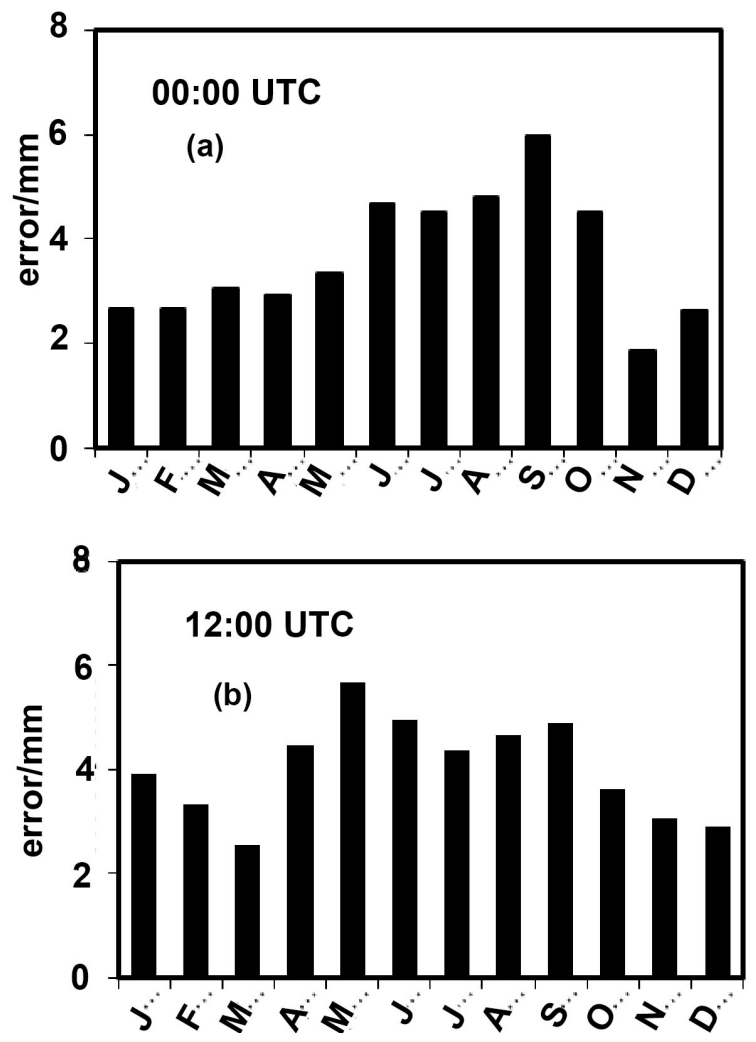

Figure 2. Monthly variance of mean bias error between GPS-PWV and RS-PWV ((a) 00:00 UTC; (b) 12:00 UTC).

Table 3. Distribution of mean error between GPS-PWV and RS-PWV over wet season and dry season in 2011 and 2012.

\begin{tabular}{cccccc}
\hline Years & $\begin{array}{c}\text { Rainy season } \\
\text { average } \\
\text { GPS-PWV/mm }\end{array}$ & $\begin{array}{c}\text { Dry season average } \\
\text { GPS-PWV/mm }\end{array}$ & $\begin{array}{c}\text { Rainy season } \\
\text { average } \\
\text { error/mm }\end{array}$ & $\begin{array}{c}\text { Dry season } \\
\text { average } \\
\text { e error/mm }\end{array}$ & $\begin{array}{c}\text { Annual average } \\
\text { monthly } \\
\text { error/mm }\end{array}$ \\
\hline 2011 & 35.0 & 13.7 & 4.5 & 2.8 & 3.7 \\
2012 & 35.1 & 13.8 & 4.7 & 3.1 & 3.9 \\
\hline
\end{tabular}

two-year GPS-PWV and RS-PWV scatter relationship between 00 and 12 o'clock (Figure 3), it can be found that the distribution of GPS-PWV and RS-PWV at 12 o'clock is more discrete than 00. 00 the goodness of fit (R2) at time and 12 o'clock was 0.96 and 0.94 , respectively.

Further statistics on the average value of GPS-PWV and RS-PWV and various error distributions at various times in two years. From the results in Table 4, there are 12-hour (night) GPS-PWV and RS-PWV averages. The average precipitation value when the value is greater than 00 (in the morning), that is, the atmospheric precipitation at night is higher than that in the morning, and the error at night is also higher than that in the morning, where the error at 12 o'clock in 2011 is $27 \%$ larger than that at 00 o'clock. In 2012, it was $11 \%$ larger. In addition, the error of GPS-PWV at both moments shows a consistent positive deviation, that is, GPS-PWV is slightly larger than RS-PWV. Some foreign 

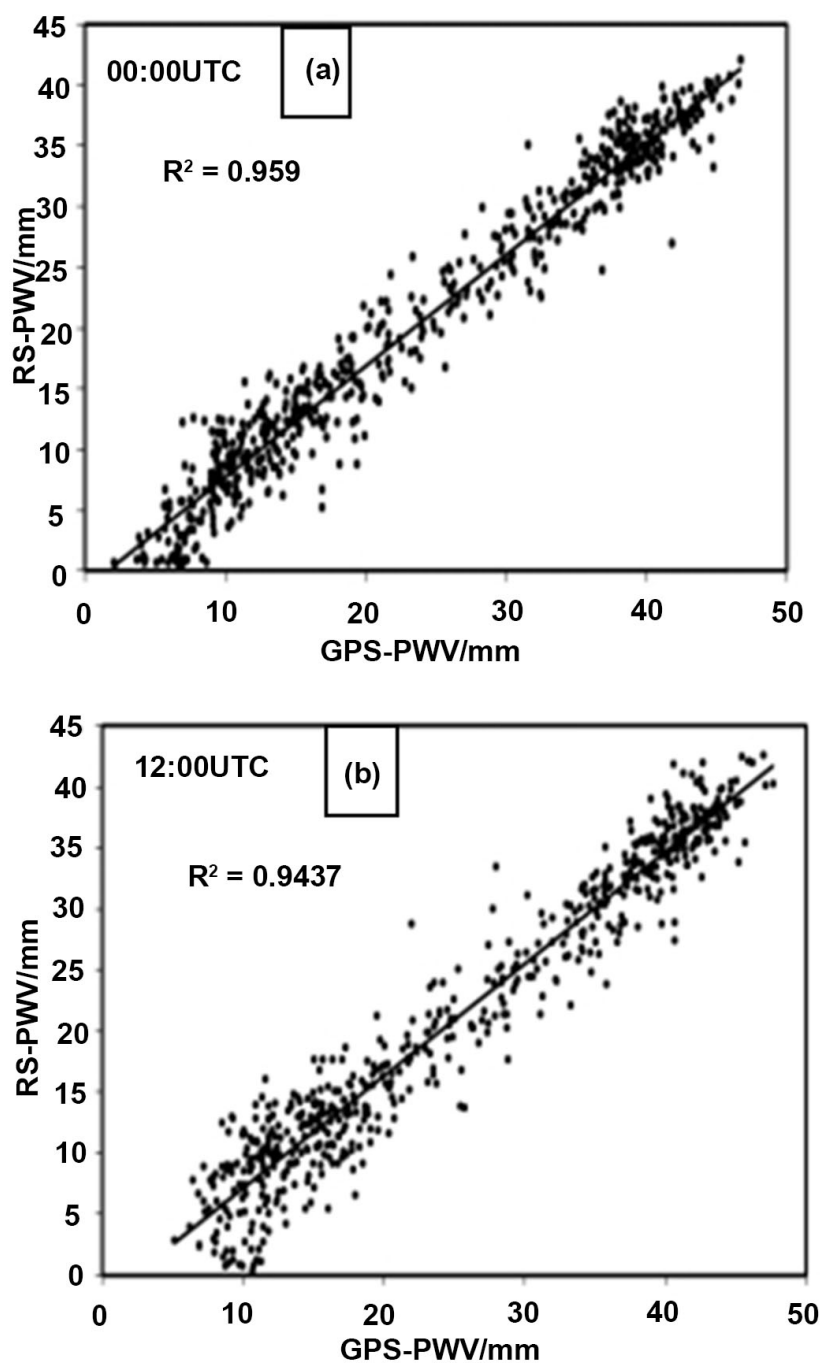

Figure 3. Scatter distribution of GPS-PWV and RS-PWV ((a) 00:00 UTC; (b) 12:00 UTC).

studies have pointed out that there is a significant "dry deviation" in the atmospheric precipitation of sounding detection in the plateau area (Takagi et al., 2000; Liu et al., 2005) and similar results have been obtained here. It can be seen from the above analysis that the GPS-PWV error is also large in the period when the atmospheric precipitation is high, and vice versa; thus, the GPS-PWV error also has a certain difference between morning and evening.

\subsection{Relationship between GPS-PWV Error and Temperature, Humidity, etc.}

In addition to significant differences in precipitation during the rainy and dry seasons, temperatures are also significantly different. The study pointed out that temperature has a certain influence on water vapor detection error ( $\mathrm{Li} \& \mathrm{Li}, 2011$; Guerova et al., 2005; Cady-Pereira et al., 2008). Explain that in addition to water vapor itself, temperature is also the cause of seasonal differences in water vapor 
Table 4. Distribution of mean and as well as the mean error, relative error between GPS-PWV and RS-PWV in 2011, 2012.

\begin{tabular}{ccccc}
\hline & \multicolumn{2}{c}{2011} & \multicolumn{2}{c}{2012} \\
\hline Time & $00: 00$ UTC & 12:00 UTC & 00:00 UTC & 12:00 UTC \\
\hline GPS-PWV average/mm & 24.08 & 25.81 & 23.26 & 25.28 \\
RS-PWV average/mm & 20.38 & 21.18 & 20.19 & 21.16 \\
Average absolute error Bias/mm & 3.20 & 4.44 & 3.62 & 4.09 \\
\hline
\end{tabular}

detection errors. It can be seen that the GPS-PWV error also has a certain relationship with the meteorological elements. To this end, each of the 30 samples with the largest and smallest errors between 00 and 12:00 in 2011-2012 was selected for the synthesis analysis of environmental elements. The statistical results show that (Table 5), when both moments show that the GPS-PWV error is large, the corresponding temperature, surface water vapor pressure and relative humidity are relatively large, and the element value is small when the error is small. Moreover, the correlation coefficients of GPS-PWV error and ground water vapor pressure, temperature and relative humidity from 2011 to 2012 were $0.37,0.32$ and 0.25 , respectively, and all passed the significance test of $\alpha=0.005$. It can be seen that the most closely related factors related to GPS-PWV error are surface water vapor pressure and temperature. This paper further analyzes the specific correspondence between temperature, surface water vapor pressure and GPS-PWV error.

For the sake of comparison, the GPS-PWV error at 00:00 and 12:00 for two years is averaged at $2^{\circ} \mathrm{C}$ and $2 \mathrm{hPa}$, respectively, and the relationship between temperature and surface water vapor pressure is obtained. It can be seen from Figure 4 that at 00 , the error rises steadily with the increase of surface water vapor pressure. The 12-hour error fluctuates first with the increase of surface water vapor pressure. When the local surface water vapor pressure reaches about 14 $\mathrm{hPa}$, the error reaches the maximum value. Then began to decline; There is a similar trend for temperature (Figure 5), but the error increases more with increasing temperature, the error seems to be more sensitive to changes in temperature, and the upward trend is more complex, and overall, There is a positive correlation between the error and the surface water vapor pressure and temperature, and the change trend at 12 o'clock is more complicated than that at 00 . The reason may be that the water vapor at 12 o'clock and the temperature are higher than 00 , and the impact on the water vapor detection error is even more Big.

\subsection{Characteristics of GPS-PWV Error in the Presence or Absence of Precipitation Days}

In addition to the above analysis of GPS-PWV error, some studies have pointed out that the GPS-PWV error is different under different water vapor conditions. Under the condition of precipitation day, the atmospheric precipitation of GPS 
Table 5. Distribution of mean surface vapor pressure, air temperature and relative humidity on highest values of mean error between GPS-PWV and RS-PWV and lowest ones.

\begin{tabular}{cccc}
\hline Meteorological element & $\begin{array}{c}\text { Surface water vapor } \\
\text { pressure/hPa }\end{array}$ & $\begin{array}{c}\text { Air } \\
\text { temperature } /{ }^{\circ} \mathrm{C}\end{array}$ & $\begin{array}{c}\text { Relative } \\
\text { humidity } / \%\end{array}$ \\
\hline 00 hours GPS-PWV error is minimal & 9.3 & 12.4 & 65.3 \\
GPS-PWV error is the largest & 16.2 & 18.2 & 77.9 \\
GPS-PWV error is minimal & 9.4 & 13.0 & 63.8 \\
GPS-PWV error is the largest & 13.6 & 16.0 & 72.2 \\
\hline
\end{tabular}
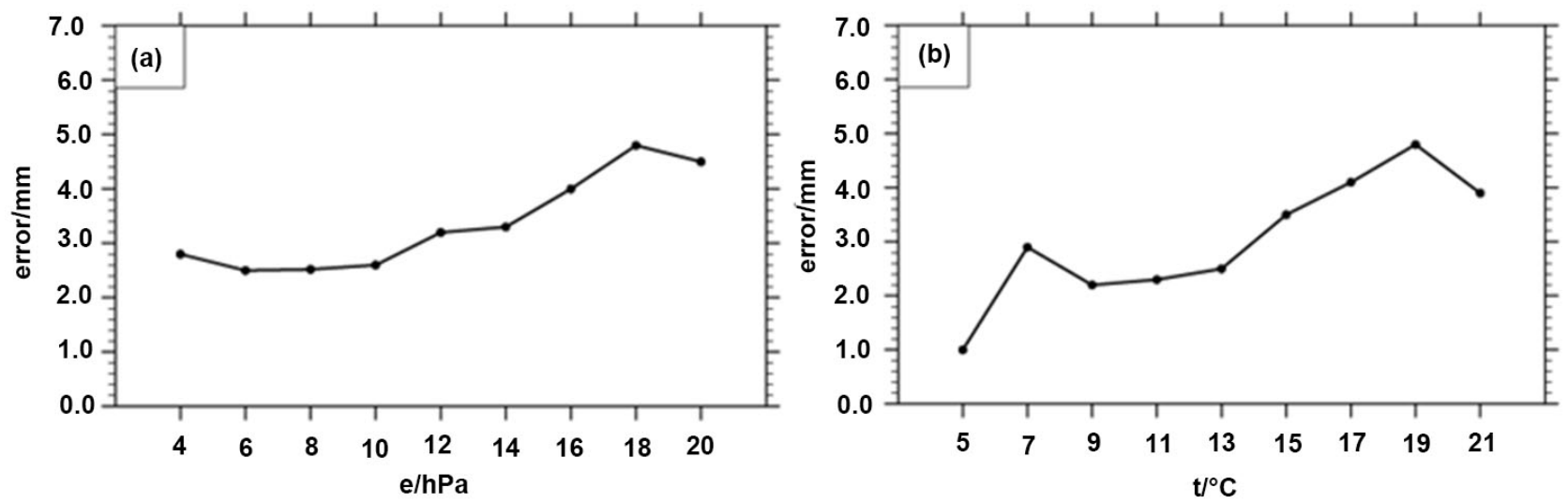

Figure 4. Changes of mean bias error between GPS-PWV and RS-PWV with surface vapor pressure ((a) 00:00 UTC; (b) 12:00 UTC).
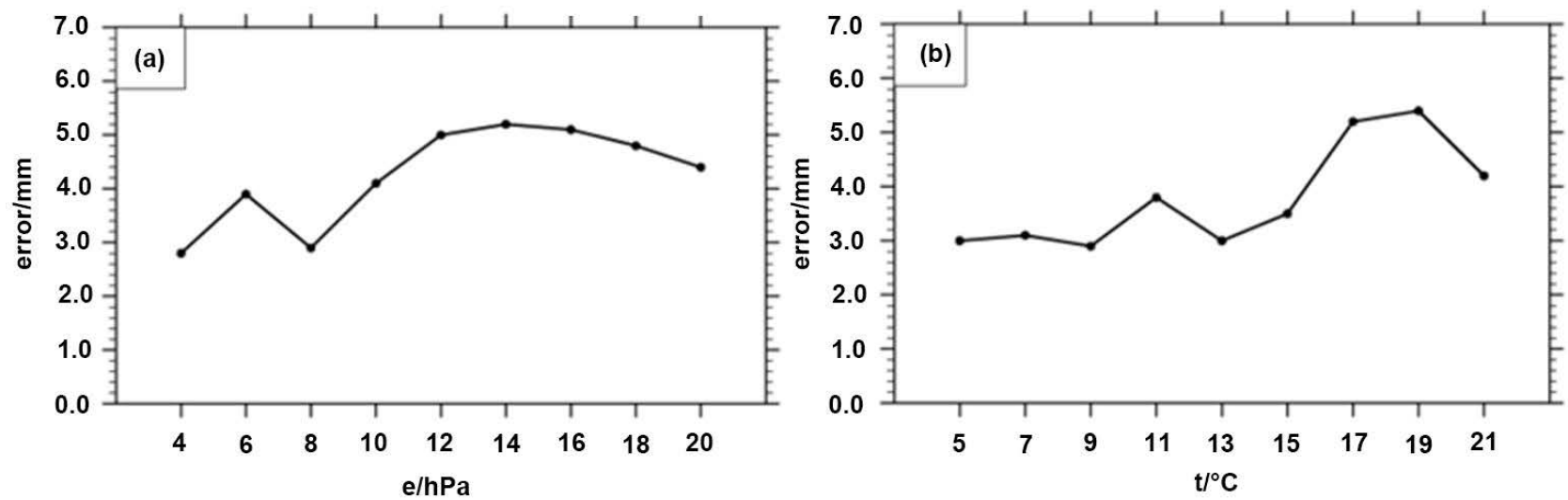

Figure 5. Changes of mean bias error between GPS-PWV and RS-PWV with surface air temperature ((a) 00:00 UTC; (b) 12:00 UTC).

remote sensing is $8.4 \%$ larger than that of sounding water vapor (Xiang et al., 2009). The correlation between GPS-PWV and RS-PWV decreases on the day of precipitation, and it is increased without precipitation (Wang et al., 2014). In order to further analyze the distribution characteristics of GPS-PWV error of Tengchong Station under different precipitation conditions, according to the lack of GPS water vapor data, The water vapor detection errors in the rainy season with and without precipitation in 2011 and 2012 were analyzed and the rela- 
tionship with the corresponding temperature and surface water vapor pressure. Among them, there is a precipitation day based on the automatic station daily precipitation calculation time: the previous day 21:00 - the same day 20:00 definition of precipitation $\geq 0.1 \mathrm{~mm}$ when there is a precipitation day (Ding et al., 2012). The error statistics of the precipitation days in the rainy season in 2011 and 2012 are shown in Table 6. Among them, in the rainy season of 2011, the errors of the days with and without precipitation were $4.16 \mathrm{~mm}$ and $3.55 \mathrm{~mm}$ respectively; the errors of the days with and without precipitation were $5.37 \mathrm{~mm}$ and $3.65 \mathrm{~mm}$ respectively. The results in 2012 were similar. On the whole, the GPS-PWV error of the morning and evening of the precipitation is greater than that of the no precipitation day. This is consistent with the previous results, because the water vapor conditions are more abundant on the day of precipitation, the error will be too large. In addition, the corresponding temperature and surface water vapor pressure analysis results show that the temperature difference between the presence and absence of precipitation is not significant, and the difference in surface water vapor pressure with or without precipitation is very obvious. There are precipitation days in 2011 and 2012. The surface water vapor pressure was $13 \%$ and $27.5 \%$ larger than the average without precipitation, and both passed the significance test of $\alpha=0.005$.

\section{Discussion}

Because the GPS remote sensing data used in this paper has a short duration, the water vapor error of the longer-term scale is not analyzed, and the qualitative analysis can only reveal the average absolute error distribution and variation characteristics of GPS-PWV. Quantitative research on water vapor detection error needs to be extended based on the data samples and GPS-PWV data of other sites around the plateau. In addition, due to the lack of data, in the time range of data selection, only a few consecutive precipitation periods meet the conditions of this section. Therefore, only a single case is listed below to discuss the relationship between GPS-PWV error and precipitation. Although the relationship between the two can be revealed to some extent, on this basis, more detailed analysis should be done after the data expansion to complete the conclusion.

Further understanding of the corresponding relationship between precipitation, atmospheric precipitation and GPS-PWV error, a specific analysis was made in 2011 when a precipitation was concentrated. Figure 6 shows the GPS-PWV and hourly precipitation and the GPS-PWV error at the corresponding time from May 28 to June 13, 2011. It can be seen that the hourly precipitation and atmospheric precipitation change are basically. It is positively correlated. In the period when precipitation occurs, the water vapor content is generally high, and before the period when precipitation is concentrated or precipitation is high, the water vapor is usually in the stage of rising accumulation, but sometimes the atmospheric precipitation may not be high. Precipitation occurs because water vapor is only a necessary condition for precipitation, but precipitation itself is closely 
Table 6. Distribution of mean bias error between GPS-PWV and RS-PWV on rainy days and clear days in 2011, 2012.

\begin{tabular}{ccccc}
\hline & \multicolumn{2}{c}{2011} & 2012 \\
\hline Time & $00: 00$ UTC & $12: 00$ UTC & $00: 00$ UTC & $12: 00$ UTC \\
\hline $\begin{array}{c}\text { Daily average error of } \\
\text { precipitation/mm }\end{array}$ & 4.16 & 5.37 & 4.97 & 4.82 \\
$\begin{array}{c}\text { Daily average error without } \\
\text { precipitation/mm }\end{array}$ & 3.55 & 3.65 & 4.09 & 4.32 \\
\hline
\end{tabular}

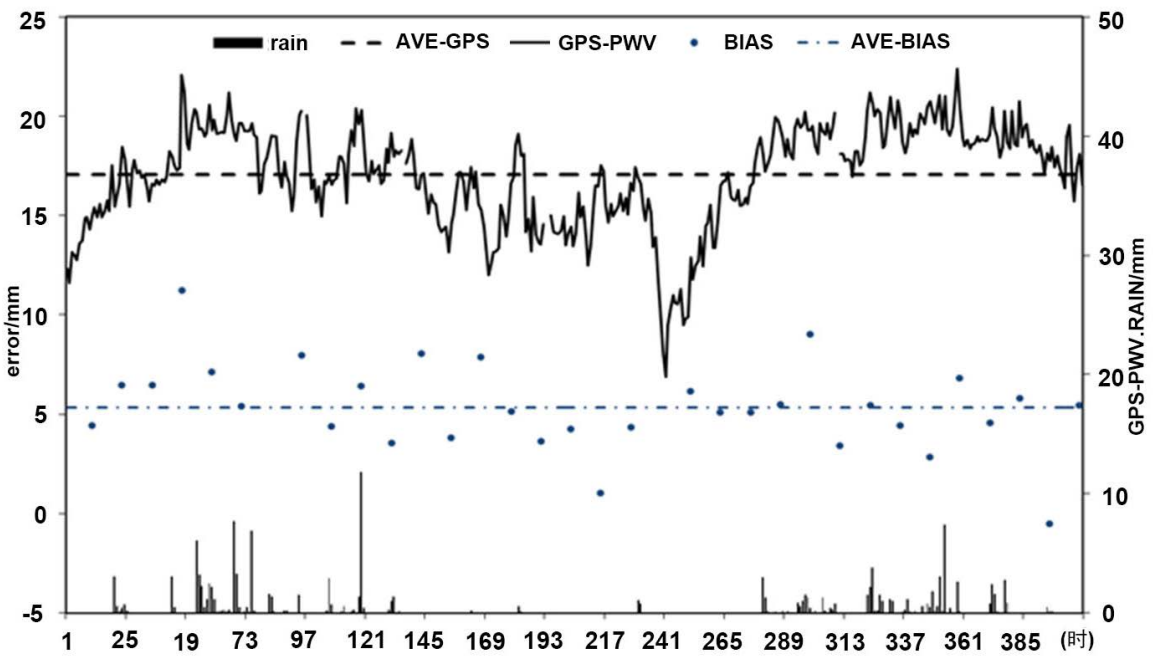

Figure 6. Hourly series of hourly GPS-PWV and precipitation, mean bias error between GPS-PWV and RS-PWV, the average of GPS-PWV and mean bias error during May 28th and JUN 17th in 2011. (Column represents precipitation, solid line represents GPS water vapor, dashed line represents GPS mean water vapor, dotted line represents mean deviation, and scattered points represent deviation).

related to other physical conditions, such as ascending motion, convergent divergence of water vapor, and physical processes of condensation. At the same time, the error of GPS-PWV also changes with the change of atmospheric precipitation and precipitation. When there is more water vapor, it may be accompanied by precipitation. At this time, the GPS-PWV error will be larger, higher than the average value of the whole period, and vice versa.

\section{Conclusion}

This paper analyzes the seasonal variation, early and late difference of GPS-PWV error between Tengchong 2011 and 2012, and its relationship with environmental factors such as temperature and ground humidity, error and atmospheric precipitation and precipitation. The main conclusions are as follows:

Tengchong Station GPS-PWV has a good correspondence with RS-PWV. Both have consistent annual variation characteristics. Among them, the water vapor is high from May to October, and low from November to April. The accuracy of GPS-PWV does not exceed $5 \mathrm{~mm}$. GPS remote sensing atmospheric 
precipitation data has high reliability in this area, and GPS-PWV is more stable than RS-PWV.

The GPS-PWV error has obvious seasonal variation characteristics, in which the rainy season (May to October) has a large error, while the dry season (November to April) has a small error.

The GPS-PWV error has a significant difference between morning and evening. At 12 o'clock (night), the atmospheric precipitation is high. At 00 o'clock (morning), the atmospheric precipitation is lower, and the GPS-PWV error at night is larger than that in the morning.

The error of GPS-PWV has a certain positive correlation with ground air temperature, surface water vapor pressure and relative humidity. When the error is large, the temperature, surface water vapor pressure and relative humidity are also large, and when the error is small, the opposite is true; it has the closest relationship with surface water vapor pressure and temperature. Both 00 and 12 o'clock have an upward trend within a certain range, and the trend at 12 o'clock is more complicated.

The error of GPS-PWV is obviously different under the condition of no precipitation, and the error of precipitation day is larger than that of no precipitation day. In 2011, the error with and without precipitation was $4.16-3.55 \mathrm{~mm}$, and the error in 2012 was $5.37-3.55 \mathrm{~mm}$.

\section{Acknowledgements}

This research was funded by the National Natural Science Foundation of China (41275095).

\section{Conflicts of Interest}

The authors declare no conflicts of interest regarding the publication of this paper.

\section{References}

Cady-Pereira, K. E., Shepard, M. W., Turner, D. D. et al. (2008). Improved Daytime Column-Integrated Precipitable Water Vapor from Vaisala Radiosonde Humidity Sensors. Journal of Atmospheric and Oceanic Technology, 25, 873-8833. https://doi.org/10.1175/2007JTECHA1027.1

Chen, X. L., Jing, H., Tong, M. R. et al. (2009). Application Accuracy and Range of Ground-Based GPS Telemetry for Atmospheric Precipitation. Meteorological Science and Technology, 37, 85-88.

Ding, H. Y., Li, Q. C., Zheng, Y. F. et al. (2012). Analysis of Water Vapor in Summer Rainstorm Using Beijing GPS Monitoring Network. Journal of Applied Meteorology, 23, 47-58.

Duan, J., Bevis, M., Fang, P. et al. (1996). GPS Meteorology: Direct Estimation of the Absolute Value of Precipitable Water. Journal of Applied Meteorology, 35, 830-838. https://doi.org/10.1175/1520-0450(1996)035<0830:GMDEOT>2.0.CO;2

Fu, R., Duan, X., Liu, J. Y. et al. (2010). Variation Characteristics of Atmospheric Precipitable Water in Yunnan Ground-Based GPS Observations. Meteorological Science and 
Technology, 38, 456-462.

Guerova, G., Brockmann, E., Schubiger, F. et al. (2005). An Integrated Assessment of Measured and Modeled Integrated Water Vapor in Switzerland for the Period 2001-03. Journal of Applied Meteorology, 44, 1033-1044. https://doi.org/10.1175/JAM2255.1

Hua, W., Zhou, B. Z., Chen, Y., Zhang, J., \& Peng, B. Z. (2007). Application of Synthetic Analysis Method in the Environmental Influence Assessment of Land General Plan. Scientia Geographica Sinica, 27, 555-560.

Li, B., \& Li, W. (2011). A Summary of the Comparative Experiment of the Eighth International Sounding System in Yangjiang. Advances in Meteorological Science and Technology, 1, 613.

Li, C. C., Mao, J. T., Li, J. G. et al. (1999). Total Remote Sensing Water Vapor of Global Positioning System. Chinese Science Bulletin, 44, 333-336. https://doi.org/10.1007/BF02886027

Li, G. P., Huang, D. F., \& Liu, B. Q. (2006). Preliminary Experiment on Remote Sensing Atmospheric Precipitation in Ground-Based GPS Observation Network in Chengdu. Journal of Wuhan University: Information Science Edition, 31, 1086-1089.

Liang, F., Li, C. C., Wang, Y. C. et al. (2003). Observation and Analysis of Atmospheric Total Water Vapor in Beijing Using Regional Ground-Based Global Positioning System. Journal of Atmospheric Sciences, 27, 236-244.

Liang, H., Liu, J. W., Zhang, J. C. et al. (2007). Inversion of Atmospheric Total Water Vapor over the Tibetan Plateau. Plateau Meteorology, 25, 1055-1063.

Liang, H., Zhang, R. H., \& Liu, J. W. (2012). Atmospheric Water Vapor Detection Error and Its Causes in the Qinghai-Tibet Plateau. Acta Meteorologica Sinica, 70, 155-164.

Liu, J., Sun, Z., \& Liang, H. (2005). Precipitable Water Vapor on the Tibetan Plateau Estimated by GPS, Radiosonde and NWP Analysis and Its Impact on Radiation Budget. Journal of Geophysical Research, 110, D17106. https://doi.org/10.1029/2004JD005715

Lu, H. G., Li, G. P., \& Jiang, J. P. (2014). Comparative Analysis of GPS, Sounding and Microwave Radiometer Water Vapor Data in Yangjiang International Sounding Test. Meteorological Science and Technology, 42, 158-163.

Ma, S. Q., Zhou, S. W., Wang, S. et al. (2016). Analysis of Diurnal Variations of Precipitable Summer Rainfall in Central and Eastern Tibet Based on GPS Data. Plateau Meteorology, 35, 318-328.

Nakanura, H., Seko, H., \& Hoji, Y. (2004). Dry Biases of Humidity Measurements from the Vaisala RS80-A and Meisei RS2-91 Radiosondes and from Ground-Based GPS. Journal of the Meteorological Society of Japan, Ser. II, 82, 277-299. https://doi.org/10.2151/jmsj.2004.277

Ohtani, R., \& Naito, I. (2000). Comparisons of GPS-Derived Precipitable Water Vapors with Radiosonde Observations in Japan. Journal of Geophysical Research: Atmospheres (1984-2012), 105, 26917-26929. https://doi.org/10.1029/2000JD900362

Ren, J. Z., Sun, J. H., Li, J. et al. (2014). Comparative Analysis of Precipitation in GPS Detection and Three Types of Reanalysis in Yunnan. Plateau Meteorology, 33, 1480-1489.

Sun, J. H., Wu, P., \& Liu, J. Y. (2013). GPS Groundwater Steam Solution and Its Accuracy Test in Yunnan. Journal of Nanjing University of Information Science and Technology: Natural Science Edition, 5, 106-112.

Takagi, T., Kimura, F., \& Kono, S. (2000). Diurnal Variation of GPS Precipitable Water at Lhasa in Premonsoon and Monsoon Periods. Journal of the Meteorological Society of Japan, 78, 175-180. https://doi.org/10.2151/jmsj1965.78.2_175

Wang, J. Z., Guo, Y. L., Xu, G. R. et al. (2014). Error Analysis of Retrieving Atmos- 
pheric Precipitable Water from Different Data in Hubei Province. Meteorology, 40, 1308-1315.

Wang, J., \& Zhang, L. (2008). Systematic Errors in Global Radiosonde Precipitable Water Data from Comparisons with Ground-Based GPS Measurements. Journal of Climate, 21, 2218-2238. https://doi.org/10.1175/2007JCLI1944.1

Wang, X. Y., Zhu, W. Y., Yan, H. J. et al. (1999). Preliminary Results of Ground-Based GPS Detection of Atmospheric Precipitable Water. Journal of Atmospheric Sciences, 23, 605-612.

Xiang, Y. C., Chen, Z. H., Xu, G. R. et al. (2009). Comparative Analysis of the Results of Three Atmospheric Precipitable Estimation Methods. Meteorology, 35, 48-54.

Yan, X. L., Zheng, X. D., Li, W. et al. (2012). Comparison of Vertical Distribution of Humidity Observations by Two Radiosondes and Their Applications. Journal of Applied Meteorology, 23, 433-440.

Zhai, P. M., \& Zhou, Q. F. (1997). Study on Climate Changes of Atmospheric Water in China. Journal of Applied Meteorology, 8, 342-351.

Zhang, F. M., \& Shen, S. H. (2008). Study on the Change of Dry and Wet Conditions and Dry and Wet Climate in China. Journal of Nanjing Institute of Meteorology, 31, 574-579. 